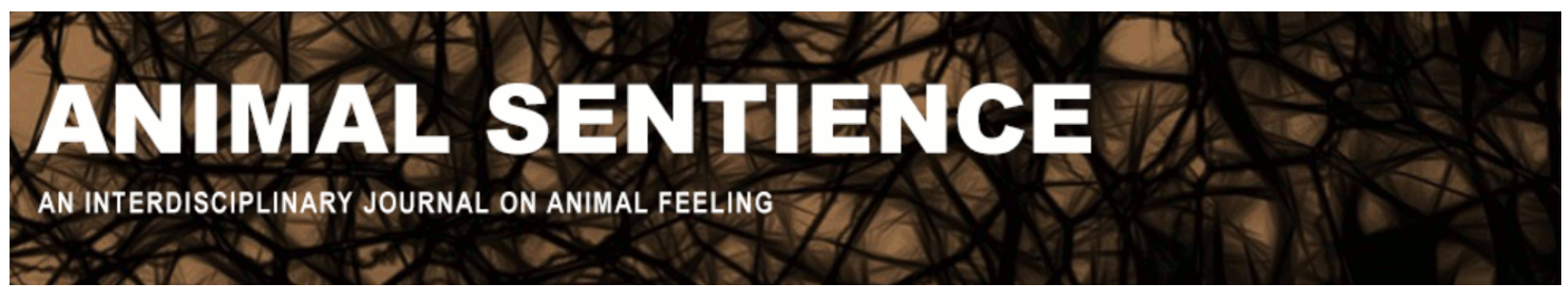

Robbins, Jesse (2020) Be wary of simple solutions to complex problems. Animal Sentience 30(16)

DOI: $10.51291 / 2377-7478.1645$

Date of submission: 2020-09-09

Date of acceptance: 2020-09-11

(c) (†)

This article has appeared in the journal Animal

Sentience, a peer-reviewed journal on animal

cognition and feeling. It has been made open access,

free for all, by WellBeing International and deposited

in the WBI Studies Repository. For more information,

please contact

wbisr-info@wellbeingintl.org.

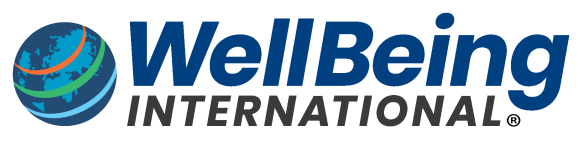

SOLUTIONS FOR PEOPLE, ANIMALS AND ENVIRONMENT 


\title{
Be wary of simple solutions to complex problems
}

Commentary on Wiebers \& Feigin on Covid Crisis

\author{
J.A. Robbins \\ lowa State University, College of Veterinary Medicine
}

\begin{abstract}
Wiebers \& Feigin purport to show that the current Covid-19 outbreak provides evidence to support a variety of public policy recommendations. Closer examination of their argument reveals a number of flaws, including a failure to adequately define terms, acknowledge counterevidence, identify value-driven trade-offs and acknowledge the logical implications of their reasoning. Scientists should attempt to address these concerns when offering public policy advice.
\end{abstract}

Jesse A. Robbins is a Post-doctoral Research Associate at lowa State University, College of Veterinary Medicine. His research addresses both empirical and conceptual issues in animal welfare and agriculture. Website

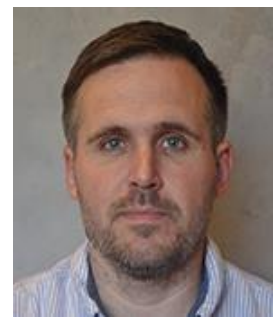

Wiebers \& Feigin $(2020 a, b)$ (W\&F) urge us to "reflect deeply" on what the current Covid-19 pandemic is telling us. The results of their reflections are as simple as they are radical - ban factory farming, hunting and the sale of certain live animals, and become vegetarians. Failure to heed this advice they tell us, will result in the "annihilation" of our species. Given the extremely high stakes, we might expect equally strong reasoning. Unfortunately, closer examination of their argument reveals significant deficiencies. In what follows, I highlight a few of the most noteworthy.

A central premise of W\&F's argument is that the rate of zoonotic disease is increasing with agricultural intensification. This claim is at odds with Smith et al (2014) who reported outbreak cases per capita are actually trending downward. W\&F fail to acknowledge this and the more general challenges associated with drawing inferences about historical disease rates (e.g. controlling for technological advancements in disease detection, reporting and monitoring). If Smith et al (2014) are correct, this presents a problem for the purported correlation between agricultural intensification and spread of zoonotic disease.

W\&F never define what they consider to be a "factory farm." The closest they come is distinguishing factory farms from family farms, asserting that the latter is preferable because they use less antibiotics. This claim about antibiotic use is puzzling - akin to claiming large hospitals use more antibiotics than smaller ones. Furthermore, if we look at the current USDA definition of family farm we find $>97 \%$ of all U.S. farms are classified as family farms (USDAERS 2019). If one is going to advocate banning certain types of farming, one should be able to define what one is seeking to ban.

W\&F fail to address numerous counterarguments to their position. They highlight the uncontroversial point that densely housing large numbers of animals increases the potential risk of infection and spread. However, they neglect to mention that such risks can be mitigated, and that such mitigation strategies are more likely to be utilized in factory farms. For example, factory farms are more likely to implement science-based biosecurity measures and tend to feature higher animal-to-caretaker ratios, hence greater limit on human-animal 
contact compared with compared with smaller, less intensive farms. This lack of close humananimal contact is one of the most common critiques leveled against factory farms by animal welfare advocates (Robbins et al 2016). Factory farms are also less likely to promote domestic - wild animal interactions (Imhoff and Baumgartner 2003; Green et al 2005) and engage in direct, farm-to-consumer sales, both of which are known risk factors for zoonotic disease transmission (Bisdorf et al 2011). Lastly, factory farming is more efficient than extensive, lowinput agricultural systems, requiring fewer resources (people, land, water, fuel, etc.), per unit of output (Capper et al 2009; 2011; 2012; 2013). In short, W\&F completely overlook serious arguments indicating that factory farms may be able to prevent and control disease better, with fewer environmental impacts, that small-scale "family farms".

W\&F's analysis is highly selective and avoids addressing its more unsavory logical implications. No mention is made of what is to be done about other pervasive forms of human-animal interactions (e.g. pet ownership, zoos, state and country fairs, biomedical research, etc.) or what is to be done about human's increasing propensity to live in denselypopulated urban centers and travel freely (Allen et al. 2017). If the goal is simply to minimize risk, presumably these too will have to be greatly restricted or banned. Perhaps W\&F omit mention of these because they think the costs of restricting such things might outweigh the benefits, which leads me to my last point.

W\&F do not consider the tradeoffs and unintended consequences of their policy prescriptions. To their credit, they acknowledge the costs imposed by China's ban on live animal markets, but quickly reassure us that the potential benefits are well worth the destruction of this $\$ 74$ billion industry. How W\&F came to this conclusion is not clear as they provide no limiting principle or criterion for determining when different forms of humananimal interactions become sufficiently risky to necessitate political action. W\&F would be on much firmer ground if they attempted to articulate the principle(s) that inform their costbenefit analysis as well as when public policy prescriptions are justified and when they are not. Without this information, we must simply take it on faith that W\&F are capable of weighing these costs and benefits in a purely objective manner - a highly dubious proposition.

In conclusion, the world is not as simple as W\&F's analysis assumes. Scientists can and should provide information about the likely consequences of different courses of action aimed at addressing the risk of zoonotic disease. However, they have an obligation to provide a full account of the relevant empirical data in all of its complexity and not just that which supports their political agenda. When scientists move beyond the role of information providers, to advocate specific policies, they must realize they are making value judgments that involve tradeoffs that may be difficult to anticipate. The pivot from one's very narrow domain of scientific expertise to far-reaching public policy prescriptions should therefore be tempered with a very large dose of skepticism and humility. This is especially the case when the policies in question entail radical lifestyle changes and the elimination of people's livelihoods and longstanding cultural traditions. 


\section{References}

Allen, T., Murray, K. A., Zambrana-Torrelio, C., Morse, S. S., Rondinini, C., Di Marco, M., ... \& Daszak, P. (2017). Global hotspots and correlates of emerging zoonotic diseases. Nature Communications, 8(1), 1-10.

Bisdorff, B., Scholhölter, J. L., Claussen, K., Pulz, M., Nowak, D., \& Radon, K. (2012). MRSAST398 in livestock farmers and neighbouring residents in a rural area in Germany. Epidemiology \& Infection, 140(10), 1800-1808.

Capper, J. L. (2013). Should we reject animal source foods to save the planet? A review of the sustainability of global livestock production. South African Journal of Animal Science, 43(3), 233-246.

Capper, J. L. (2012). Is the grass always greener? Comparing the environmental impact of conventional, natural and grass-fed beef production systems. Animals, 2(2), 127-143.

Capper, J. L. (2011). Replacing rose-tinted spectacles with a high-powered microscope: The historical versus modern carbon footprint of animal agriculture. Animal Frontiers, 1(1), 26-32.

Capper, J. L., Cady, R. A., \& Bauman, D. E. (2009). The environmental impact of dairy production: 1944 compared with 2007. Journal of Animal Science, 87(6), 2160-2167.

Green, R. E., Cornell, S. J., Scharlemann, J. P., \& Balmford, A. (2005). Farming and the fate of wild nature. science, 307(5709), 550-555.

Imhoff, D., \& Baumgartner, J. A. (2003). Farming with the Wild. Enhancing biodiversity of farms and ranches. Healdsburg, CA: Watershed Media.

Robbins, J. A., Von Keyserlingk, M. A. G., Fraser, D., \& Weary, D. M. (2016). Invited review: Farm size and animal welfare. Journal of Animal Science, 94(12), 5439-5455.

Smith, K. F., Goldberg, M., Rosenthal, S., Carlson, L., Chen, J., Chen, C., \& Ramachandran, S. (2014). Global rise in human infectious disease outbreaks. Journal of the Royal Society Interface, 11(101), 20140950.

USDA - ERS. Farm Household Well-being (2019)

Wiebers, DO \& Feigin, VL (2020a) What the COVID-19 crisis is telling humanity. Neuroepidemiology 54(4): 283-286.

Wiebers, D.O. \& Feigin, VL (2020b) What the COVID-19 crisis is telling humanity. Animal Sentience 30(1) 